\title{
Current status of audit on board ferry services operating between Labuan and Mainland (Sabah, Sarawak and Brunei)
}

\begin{abstract}
This study is concerned with evaluating the seaworthiness of ferry services between Labuan and Mainland (Sabah, Sarawak, Brunei) Labuan provides services to 2500 passengers a day Department and the number spikes during festive seasons. The audit tools were adopted from the Marine Department and surveyor list. Nine ferry services were audited for seaworthiness based on ship's structure, machinery, fire safety measures, remote control and warning system, life saving appliances, radio communications, remote control and warning system, safety of navigations and accommodation and escape measures. The audit shows that the ships generally comply to the rules on minimum requirements for life saving appliances (LSA) at medium level except on some boats the Hydrostatics Release Unit (HRU) were wired and this cam prevent the life-raft to self-inflate when submerged in water. It is suggested that standard design for speedboat hull needs to be introduced.
\end{abstract}

Keyword: Ferry services; Labuan; Passenger ferry; Vessel audit 